\title{
Electronic Information and Research Library Technical Services
}

\author{
Peter S. Graham
}

The relation of libraries to the electronic information explosion has been a focus of discussion for several years, but the impact of this explosion on the technical services function within libraries has not been adequately explored. In what follows, my contention is that technical services are not solely dependent on decisions their libraries make regarding electronic information. They should be a driving agent as well.

\section{ISSUES AND CONTEXTS}

Some of the new contexts in which our research libraries technical services departments operate include the following:

1. First, the electronic library is coming into being within the context of the university: information in electronic form is increasing in importance. For a full development of this context, see the excellent article by David Lewis, "Inventing the Electronic University."

Larger and larger quantities of information are appearing electronically, although they are still small in proportion to the quantities we expect in a few years. Online databases are now numbered in the thousands with hundreds more appearing each year. Local academic files of electronic information are being created at a rate that no one can guess; and CDROMs versions of over two hundred databases have been published. ${ }^{2}$ Most CDROMs are indexes such as Current Contents, InfoTrac, PsycLit, and Medline, but textual and statistical data are also being published in this form; for example census data, the Oxford English Dictionary, the Medieval and Early Modern Data Bank, and the Thesaurus Linguae Graecae.
Then there is e-mail: Bitnet, Arpanet, Internet, NSFnet, NYSERnet, ALAnet, AppleLink, Compuserve and The Source are all in heavy use among scholars and many other groups. It is hard to know how much data goes over these lines in addition to correspondence. We do know that Kermit, the communications program developed at Columbia University, is enormously popular among academics, and one of its virtues is its file-transfer capability. ${ }^{3}$

There is greatly increased use of electronic information at some of our universities. This is especially true at campuses where the computing services have facilitated its availability by providing communication networks, e.g., Michigan, Stanford, Carnegie-Mellon.

2. There is broad OPAC availability. There is, however, wide variation in how these are made available to patrons: inbuilding only, library star networks, dialup access, limited LAN availability, and campus-wide network access. Wide campus OPAC availability is generally viewed as a desideratum.

3. The automation of technical services has largely been accomplished and related issues are fully understood. There are few

Peter S. Graham is Associate Vice President for Information Services and Associate University Librarian for Technical and Automated Services, Rutgers University Libraries, New Brunswick, New Jersey 08903. 
libraries in the country that have not been automated to some extent. Meanwhile, it is also evident that the present level of automation cannot keep up with traditional tasks. One example is the British Library's recent announcement that it would cut by one half the fullness of much of its cataloging in order to process the remainder more promptly.

\section{"Our traditional staffing definitions are more and more open to ques- tion."}

4. Our traditional staffing definitions are more and more open to question. There is difficulty now in finding technical services staff, especially catalogers, who have the bibliographic skills, the judgment, and the managerial skills we need. We also need staff who have skills and experience with electronic technology or have the selfstarting ability to obtain them quickly.

When we do find good staff they are often very good indeed; but the supply is limited.

5. Friendly interfaces: The concept of the integrated information system is fading. Historically, our goal in technical services has been to provide the user with a single place to search and a single tool. But just as we began to want an integrated monographic acquisitions, cataloging and circulation system, the idea of linking abstractand-index databases to serials holdings raised our expectations. We now know that we will never have all necessary information accessible through a single file. We need to turn our attention to user-friendly interfaces.

6. MRDFs, or computer files: Most research libraries are cataloging machinereadable data files. Some have only cataloged a few. Some libraries are providing bibliographic access to large quantities of commercial and private databases, both for those owned by the library and for those not owned, with very considerable implications for change in what libraries are and how we do things.

7. Electronic publishing: There isn't much yet but it will grow. Libraries will presumably have to provide access.

8. On-site commercial databases: Many campuses are now mounting major commercial databases locally to provide onsite searching. The universities include Carnegie-Mellon, University of Pennsylvania, Columbia, Georgia Tech, Stanford, and Rutgers. These databases are often linked to other types of library information. Access to these databases can be through the OPAC and other library offerings.

9. Local information files: Job files, fellowship announcements, campus events, news, advice sources, research in progress, housing files, community information, vertical file-like files are increasingly being made electronically available on campus, often through the library system or one adjacent to it. These may be linked to the OPAC.

10. Full-text in electronic form is becoming more common. Special libraries have long sought to provide full-text information. It is technically possible to have library information systems that provide full electronic texts. Facsimile transmission is an early manifestation of this possibility; so is the development of broadband image transmission from media centers. The libraries at Rutgers and Princeton have been funded by the National Endowment for the Humanities, (NEH) to plan a Center for Machine-Readable Texts in the Humanities. Various forms of optical disk (CD-Rom, WORM) and high-density magnetic storage, and high-bandwidth transmission systems will increase the technological attractiveness of full-text provision.

11. Information immediacy is increasing: Libraries must provide more timely access to information. The timeliness of access can be arrayed on a continuum from the immediate to the archival. (On the one hand we have provided quick access to recent data, and on the other we have provided slower access to historical knowledge.) Typically, our bibliographic access tools have been effective in inverse proportion to the timeliness requirement of the information. Electronic information places a premium on immediacy of access 
to information, but our techniques for creating bibliographic tools are best equipped for the archival. This must change if libraries are to be properly effective.

\section{TECHNICAL SERVICES DEFINITIONS}

Technical services of libraries are primarily responsible for the acquisition of materials and their organization. For pragmatic reasons both circulation systems and preservation activities have sometimes been included in the technical services responsibility. But in general the purview of technical services has been recognized as the buying and receiving of selected materials, and their organization for use: acquisitions, gifts and exchange, serials control, cataloging: from selection to shelf, mark it and park it. Up until very recently, technology has not changed that mission.

There are three distinctive but implicit assumptions in the traditional technical services role that can no longer be taken for granted.

Prediction of use: The traditional role calls for information provision predictive of use. The great bulk of the information provided by libraries has been acquired in advance of expected need on behalf of users who did not yet know of their need. Prediction of use has been both the pride and the bane of collection development policies-one need only mention the Pittsburgh study-and it is the driving force behind cooperative programs at all levels. The best interests of our users require us to predict their needs as best we can; however, provision of information on demand can be expected to rise with the availability of electronic information, requiring much more responsive acquisition and delivery systems.

Ownership: The traditional technical services role assumes library ownership of information. A library acquires information, then organizes it, makes it available, and preserves it. However, we increasingly recognize that there is information not owned by the library that we must make available to our users. We have done this in the past for serials we haven't owned, through our printed journal indexes; we are increasingly making this happen through what we call our catalogs. This includes catalog information about the full range of GPO documents, the databases in the computer center, or the holdings of the Center for Research Libraries.

Hard copy: Our traditional technical service role has assumed hard copy. We have traditionally bought and cataloged books, journals, films, tapes, records, floppy disks and CD-ROMs. We now must confront library and user needs for access to machine-readable files that have extremely itinerant lives. At Rutgers, for example, is being cataloged in the library instructional software owned by the computer center. Kinko's and IBM issue these programs on individual floppy disks; but in the Rutgers pilot program, the computer center is maintaining them all on hard disks for examination, and is issuing loan copies to faculty who wish to evaluate them. Immediately thrown out was any idea of added copy cataloging; but that was the easy decision. What happens with software upgrades? What happens now that Kinko is no longer cooperating with Apple? Where is this stuff going to be located next year, or next week? And with other materials-which copy of the ICPSR survey research data should we be cataloging? What kind of access record do we provide to the Medieval Data Bank information?

Mark it and park it? Mark what, and park it where?

\section{NEW TASKS FOR TECHNICAL SERVICES}

New contexts and the changing of traditional assumptions imply a wide range of new understandings and activities for technical services. Most of us recognize this, and discussion and change has been widespread in research libraries. Information interfacing and intellectual preservation are two of the most interesting issues being discussed in research libraries.

1. Linking access systems. The goal of the integrated bibliographic system, that seamless database allowing access to all resources is fading. We cannot provide "one-stop shopping" (and it should be remembered that the term's usage is from 
stores that wish to persuade us that what they happen to have is all we need). It is increasingly necessary to envision linked information systems rather than integrated ones. $^{4}$

Consider the multiplicity of information sources we must provide to patrons: the OPAC itself, acquisitions files, serials control systems; government document files, technical reports, vertical files, media centers; remote search services, OCLC, special databases in RLIN, local databases; CD-ROMs, ICPSR files at computer centers, and campus information systems. Research libraries are the institutions to provide patron access to all this information, and we can never seamlessly present it all.

We will have to determine the principles by which we intelligently present this array of information to users, and then we must find ways to implement them. To do this we will require librarians equipped with both technological expertise and bibliographic understanding. These librarians will continue to embody the service goals our profession has always held high.

They will find challenge in knotty technical problems (the kind that used to be found in formulating and implementing cataloging codes and the MARC record), and they will find satisfaction through the resolution of these problems in favor of patron service. For these librarians, the technical problems will simply have different characteristics. In this future will be found our response to the reported dearth of librarians interested in cataloging and technical services. ${ }^{5}$

An example of a knotty problem for linked information systems is authority control. One of the most important intellectual contributions librarians have made to information access is the concept of the controlled thesaurus, or authorized vocabulary. Providing syndetic structures and authority files for great catalogs of millions of entries require enormous effort, and we are just getting the issues under control in our automated cataloging systems and OPACs.

Consider now the problems facing a patron who is moving his or her search from the government documents catalog to the OPAC, and perhaps to the ERIC database or to Chemical Abstracts. The search movement should be immediate and the interfaces should assist rather than assault the user. But is it also possible to address the shifts in controlled vocabularies as the patron moves from one database to another? The challenge for serious and technically minded librarians is great.

2. Intellectual Preservation. The second new task for technical services is intellectual preservation. Intellectual preservation is different from preservation of a physical artifact. Intellectual preservation addresses the transience, the evanescence, the fundamental ephemerality of electronic information. The Bodleian Library at Oxford maintains the John Johnson Collection of Printed Ephemera, but this is for materials explicitly intended for short lives. All our research libraries are about to include collections of electronic ephemera: material intended to live, but in a form conducive to destruction.

Ed Brownrigg, Gordon Neavill, and others have commented on the intellectual risks involved in committing our discourse to the fragile yet fertile medium of electronic recording. ${ }^{6,7}$ It is obvious to all of us from personal experience that electronic information can be easily lost.

The proliferation of versions of texts is another problem. Even in print form, it has long troubled scholars, bibliographers, and librarians. Ithiel de Sola Pool has commented on the new possibilities in an electronic age, as easily reproducible texts and versions of texts are transmitted back and forth across academe. ${ }^{8}$ The concept of a canonical text-already in trouble in printed forms-could cease to exist altogether. At the personal level, many of us have already had the experience of distributing memos in draft form over e-mail to various colleagues for response, with variations in the drafts following hard upon one another as the comments come in.

De Sola Pool is concerned about this issue in terms of redactions of literary forms, both for texts of the past (consider for example the current scandal over the text of Joyce's Ulysses) $)^{9}$ and also for those 


\section{Electronic Information-Malleability and Responsibility}

The malleability of information that is one of the major advantages of computerbased electronic systems has as its corollary the potential transience of information. ... Proponents of computer-based electronic systems have not addressed the issue of the long-term survival of information. . . . The survival of information in an electronic environment becomes an intellectual and technological problem in its own right. . . . So long as intellectual works are recorded in tangible form, the primary responsibility for defining and shaping a society's stock of knowledge rests with its librarians.

-Gordon B. Neavill, "Electronic Publishing, Libraries, and the Survival of Information", LRTS 28:76-89 (Jan. 1984)

[They] keep talking up IBM's . . still unannounced document-management software. Running on the mainframe, the RMS software automatically rids an OfficeVision system of documents no one wants anymore. Users can designate individual documents to be held indefinitely, but otherwise, the system relies upon userdefined time frames or the system's own default values to regularly prune documents.

Not only does RMS reduce the need to buy additional storage as the years roll by .... it also helps make possible the elusive paperless office! Don't tell the printer people.

-Spencer F. Katt, "Rumor Central," PC Week July 24, 1989, p.112.

I thought it important to note that whereas the advent of the printing press had once stabilized our texts by removing the pitfalls inherent in manual copying, the computer now renders the modification of electronic materials by the ordinary user almost child's play. I thought it important also to stress that unless continuous efforts are made to control the integrity of TLG materials now in circulation, a multiplicity of electronic text versions will soon be inundating the field, and before long an apparatus criticus to electronic texts will become a necessity.... Most electronic data users . . . do not wish to deal with such issues and problems; in fact, many of them do not understand (or-worse yet-do not care about) them. Someone must, lest recent progress in Classics be stifled, or even reversed.

-Theodore F. Brunner, Director, Thesaurus Linguae Graecae, Newsletter No. 15 (July 1989), p.1-2.

In her inaugural address ... Berger talked about information access leading the pack of issues identified as critical to ALA members. . . . "In a democracy, information access requires an information base secure from intrusion, distortion, and destruction; one protected from both physical and technological deterioration. . . ." She talked about preserving the printed word, but also census tapes, Presidential tapes and other non-print information, and above all, computer security.

- "Patricia Wilson Berger Inaugurated as ALA's President, " Library Hotline V.18 No.27, p.1 (July 10, 1989). 
of the future. I have heard otherwise responsible scholars speak of the desirability of changing established texts to suit immediate needs or to "improve" them for specific purposes. De Sola Pool speaks of such textual proliferation as overwhelming a true identification of what is, in fact, the world's literature.

Will this be the case? Will scholarship stand for it? Will libraries? Libraries and librarians should help to see that it not happen. And we should do more than just stick a finger in the dyke. Someone must provide mechanisms to establish and maintain firm electronic texts. Librarians are in fact well placed, for historical and functional reasons, to assure that a body of knowledge can be identified, and to provide the means to assure that society's intellectual growth is not based on shifting sands.

The great asset of information in electronic form is also its great liability. Gordon Neavill speaks of the "malleability" of electronic information; that is, its ability to be easily transformed and manipulated. ${ }^{10}$ Electronic manipulation, while desirable, is a two-edged sword: information that is easily changed is easily lost.

\section{"Neavill identifies three ways in which information can be endan- gered through its existence in elec- tronic form."}

Neavill identifies three ways in which information can be endangered through its existence in electronic form: ${ }^{11}$

First, formal contributions to scholarly literature that are apparently in low demand may intentionally be purged. Gerald Salton of Cornell, among others, has written in favor of this for less interesting items and those less wanted. ${ }^{12}$ There are cost-effectiveness issues at play here; in a print collection, purging unused materials is an expensive proposition to identify, physically remove, and delete from the various records. The same is true for electronic information. The space to store print materials doesn't cost much in to- day's library accounting schemes, but is a very specific and budgeted cost for electronic systems.

Second, unpublished electronic writings that could have secondary, later historical use are more likely than paper to be purged as of no further primary use. These are the kinds of ephemeral writings that in the past have eventually found their way into archives or special collections: drafts of novels, pre-contractual negotiation papers, and even certain classes of White House memoranda. ${ }^{13}$

The third way in which information can be intentionally endangered is through the updating of noncurrent information. Examples include publisher lists, annual data handbooks, short-term economic data, and outdated versions of computer software (especially where it is only distributed electronically, as for example Kermit). As we reach pure electronic publishing, where hard-copy is not produced, such cases will become more and more frequent. (A recent bellwether example is the difficulty the Museum of the Moving Image has just found in locating video games less than ten years old.) ${ }^{14}$

So far these examples only address the "keep or lose" possibility: either we keep the particular data set or we lose it in its entirety. There is a more insidious danger, and that is the danger of data modification. Such modification may be legitimate and public, or it may be illicit and fraudulent. Both cases present libraries with problems. A legitimate modification of data might exist, for example, as Books in Print is updated to reflect changing inventories. If - when - the database exists only electronically, what is the possibility of maintaining an archival record of the publishing industry? And whose responsibility will it be?

For scholars, lawyers, business people, and bureaucrats we have until now had confidence that in a printed work my text will be the same as your text, and that my page reference will guide me to the same information as yours. Now, however, the transience of data prevents the assumption that my copy is the same as your copy. This will present one set of problems for business and government, and a 
similar but more long-range set of problems for scholarship.

The case will also exist of fraudulent and opportunistic modification of data. Consider an electronic publication as a result of which the author is sued for libel; and consider the possibility of the author then modifying the offending text. What happens to the lawsuit? What happens to the intellectual integrity of the text and its distributed copies?

We know that integrity has been wanting recently at almost every level of government and in many business institutions, so we know we can anticipate conscious manipulation of data from these sources. Academia is not pure either, as the pressures of ambition and tenure have already led to the falsification of experimental data and reports.

We need tools to assure the integrity of electronic information; not only to preserve versions of texts, but to preserve them in unmodified form. (Let me sketchily suggest the exploration of document checksums, calculated using letter and spacing values and maintained as part of every document, according to a standard adhered to by major word-processing vendors that would manage to ignore the effect of purely formatting information.)

If such tools are not provided, although librarians are well placed to provide them, then scholarship and intellectual life will be damaged in two ways. Scholars and students will become cynical and skeptical; and as a consequence society's scientific and intellectual growth will be slowed.

As Neavill says, electronic publishing proponets so far "have not addressed the issue of the long-term survival of information. . . . The survival of information in an electronic environment becomes an intellectual and technological problem in its own right." If we want to assure permanence of the intellectual record that is published electronically, he urges, then it will be necessary consciously to design and build mechanisms within electronic systems in order to do so. ${ }^{15}$

Physical preservation of media is one thing. Intellectual preservation is another. In electronic publishing, how will revi- sions be made (and how will libraries record them) $?^{16}$ Who in research libraries should be responsible for monitoring the volatility of electronic information? In "circulation" of electronic information, for what safeguards is the library responsible?

Is data manipulation and electronic fraud a library concern? If so, is it a technical services concern? If not, whose is it?

\section{OPTIONS FOR RESEARCH LIBRARIES IN AN ERA OF ELECTRONIC INFORMATION}

There are four potential models for technical service operations in large libraries in a technological era:

1. Do nothing, or little: In this model, a library continues traditional acquisition and information provision patterns. Virtually all research libraries will do more than this.

For a library that follows this path, however, the consequence for technical services will be stagnation. Patrons will go elsewhere for much of their information. Technical services will remain highly significant within a less significant institution.

2. Expand access to electronic materials: Continue to purchase hard copy, but also acquire electronic data and provide expanded access to off-site information. Most research libraries are taking on this task. Some regard it as the end, not the beginning, of what they do, at least for technical services. Y.T. Feng's prediction of its limited role is that "technical services will continue to keep somewhat its traditional bibliographic orientation, but with more and more dependence on electronic technology to improve efficiency and to facilitate cooperation. ${ }^{\prime \prime 17}$

In this option, the hard-copy acquisition and cataloging activities will become proportionally smaller than at present, information access is considered an issue primarily left to the public service librarians, and the importance of traditional technical services functions will proportionally decrease.

If the traditional functions are all that are maintained, technical services will become a kind of personnel backwater as it 
"If the traditional functions are all that are maintained, technical services will become a kind of personnel backwater as it congeals into a ruledriven decadence."

congeals into a rule-driven decadence. Traditional technical services will never disappear, for hard-copy needs are foreseeable indefinitely; and certain standard technological requirements will continue, as for example the provision of OPACs. But as is already happening, technical functions are becoming routinized as they become better understood and automated.

3. Develop interfaces: If technical services take on the task of providing intelligent interfaces between access systems, then this necessary patron service will provide a natural growth pattern for our trained and future staffs. The skills we regard highly now will be supplemented by further technological skills. By their nature these new skills will require effective communication and transmission throughout the library, reinforcing and enhancing the traditional role of technical services at the center of information provision to librarians and patrons. As John Sack has suggested, "the role of the integrator of such systems may be the professional high ground." ${ }^{18}$

There is a danger that a caste system will develop: a few professional experts could become counterposed to journeyman catalogers. (We see something like this now where separate library systems offices exist.) It is up to all our professionals and to management to see that this does not occur; not only would it be unnecessarily divisive, but it would inhibit the provision of the most effective access to information.

4. Assert institutional responsibility for the preservation of knowledge: This is the most difficult model of the four, and the most speculative.

For libraries to take on the preservation of knowledge, and not just of artifacts, may seem simply to be an extension of our existing role in the classic paradigm (ac-

quire, organize, make available, and preserve). I believe however that it will be different and more difficult. The obstacles include the financial, the technological, and the social. Because in preserving electronic information we may be attempting to go upstream against the current of technologically and socially established throw-away patterns, the task may be impossible.

Archiving of information solely in electronic form is a recent development, but will grow. Much U.S. census information will be preserved only in this way. The director of corporate technology of Xerox says "Paper is portable, disposable, comfortable to use, and cheap. It will, however, lose its role as an archiving medium. The 'truth', the up-to-date information, will not be on paper but in electronic form. ${ }^{19}$ An Educom task force has initiated discussion of serious aspects of the intellectual property issue with the intent of expanding the concepts both of authorship and of intellectual access beyond the constraints imposed by the history of print. ${ }^{20}$ In these developments the preservation of electronic information from taint is not addressed, though some scholars and librarians are beginning to call attention to the problem (see sidebar).

Librarians' acts of preservation have always been upon objects we have owned. To protect information we will continue to require some title over it. We need to approach the intellectual property issue with the following understanding: society must grant libraries some form of trusteeship over knowledge if society wishes knowledge to be preserved.

Libraries-and our parent institutionsmust be prepared to pay in part for this privilege and responsibility. It will not be easy to confront the information industry with this concept; it will be desirable rather to work out a common understanding of rights and responsibilities if libraries are to take over a preservative function while the return on investment for information creators remains appropriately in their hands. It will require the intelligent political action of libraries, universities, civic groups and public bodies, and vendors to work out an acceptable form of knowledge trusteeship. 
Another way to preserve information and to maintain trusteeship over it is, of course, to create it in the first place. For example, libraries could actively become publishers, or at least distributors, of electronic forms of certain data. The Research Libraries Group is in some respects taking on this role with the Eighteenth Century Short Title Catalog, the Avery Index, and the MEMDB. The National Library of Medicine has long done so with Medline. Universities and other public agencies responsible for libraries need to take seriously the idea of information ownership. There is a confluence of interests on this issue and the serials pricing crisis. For cost reasons this has also led to proposals for universities to assert trusteeship over the information they create. ${ }^{21}$

The Association of Research Libraries has suggested that university presses should again consider taking over publication of journals. Academic libraries might well begin considering the publication of electronic journals, thereby actively becoming part of the electronic information distribution process. Aside from the advantage of directly maintaining trusteeship over the information, this would allow libraries to learn the pitfalls and the opportunities of the process, and to be part of the dialogue that is changing the face of information transfer. Libraries are in a good position to provide the technical facilities that are necessary for electronic publication: we have ready to hand the information itself, the computing services, and the literate and numerate editors, information compilers and database managers. As James Thompson has suggested in an acute article on serials pricing, it may be time for "the idea of the academy retaking control of the bulk of scholarly publishing. ",22

\section{SUMMARY AND CONCLUSION}

I have suggested several possibilities for technical services roles in the coming period, broadly comprising stagnation, expansion, and innovation. In the latter two models, the role of technical services is to become more technologically adept. There is a need for a congruence of systems and of bibliographic skills and organization within libraries. This is happening in many larger libraries, as the same people have become responsible for both sets of skills.

Understanding and implementing the preservation of electronic data will lead to increasing sophistication within library staffs about systems, hardware and software, copying techniques, backup mechanisms, optical technology, networking, and data transfer. But it will also lead to increasing sophistication about legal issues, technology transfer, intellectual property, and information provision. These knotty problems will actually aid us in attracting the staff we need who will want to rise to these challenges. For technical services, the medium becomes the message as never before.

If libraries are to become active agents in the electronic revolution, once again asserting curatorial responsibility over information in all its forms, then the technical service function must transform itself. Electronic information is going to thrust change upon technical services. As a consequence, technical services units will either stagnate or transform themselves along with their libraries; they are unlikely to remain similar to what they have been in the past decade.

\section{REFERENCES AND NOTES}

1. David W. Lewis, "Inventing the Electronic University," College \& Research Libraries 49:291-304 (July 1988). Additional important readings include: Caroline Arms, ed., Campus Networking Strategies (n.p.: Digital Press: 1988); and the Research Libraries Group Local Systems Planning Committee, Agenda for October 7, 1988 Meeting; includes returns of "RLIN Needs Assessment Survey." See esp. Colorado State, Stanford, Yale.

2. Susan A. Motley, "Optical Disc Technology and Libraries: A Review of the 1988 Literature," CDROM Librarian 4:12 (May 1989). 
3. A harbinger for the future of Kermit and similar programs is attested to by plans to include it in the read-only memory of 250,000 personal computers to be "manufactured and delivered to Soviet secondary schools as part of the current five-year plan. . . ." Info-Kermit Digest 9 (13 June 1989), s.v. Kermit Conference Report (this reference is to an electronically distributed journal which, as it happens, lacks pagination).

4. I'm talking here about a public access system, not about an integrated processing system, still a desideratum for handling traditional acquisitions, cataloging, serials, and circulation functions.

5. For a discussion both of the scholars' need and the kind of activity that will satisfy it, see Donald Langenberg, "Supporting the Global Scholar," Academic Computing 3:12-16, esp. p.15.

6. Edwin Brownrigg, Clifford Lynch, and Mary Engle, "Technical Services in the Age of Electronic

- Publishing," Library Resources \& Technical Services 28:59-67 (Jan. 1984).

7. Gordon B. Neavill, "Electronic Publishing, Libraries, and the Survival of Information," Library Resources \& Technical Services 28:76-89 (Jan. 1984).

8. Ithiel de Sola Pool, "The Culture of Electronic Print," Daedalus 111:27-28 (Fall 1982).

9. For a summary at one stage of the ongoing dispute, see Charles Roman, 'The New 'Ulysses': The Hidden Controversy," New York Review of Books, December 8, 1988.

10. Neavill, p.77. Professor Harvey Wheeler, of the University of Southern California, in a keynote speech at the October 1988 LITA conference, spoke of the "fungibility" of information. I think this is an incorrect use of the term, as it implies that one piece of information is just as good as another; and I think its use reflects Wheeler's lack of concern for firm texts, and explicit enthusiasm for the riot of change that becomes possible.

11. Neavill, p.81.

12. Gerald Salton, Dynamic Information and Library Processing (Englewood Cliffs, N.J.: Prentice-Hall, 1975), p.16.

13. I'm referring of course to the attempted deletions that took place during the Iran-Contra scandal. See also Roberto Suro, "Tapes on Alaska's Oil Spill Erased by Exxon Technician," The New York Times (July 2, 1989), p.14.

14. Glenn Collins, "An Archeological Hunt for 'Old' Video Games," The New York Times (June 19, 1989), p.C11,C16.

15. Neavill, p.78.

16. For a knowledgeable summary of the process and problems in keeping track of authorial and editorial revisions, see Thomas W. Smith, "Desktop Publishing in the University: Current Progress, Future Visions," Academic Computing 3:26-36 (May 1989).

17. Yen-Tsai Feng, "Technical and Reader Services for the Research Library-The Challenge for the Next Decade," Journal of Library and Information Science 13:54 (April 1987).

18. John R. Sack, "Open Systems for Open Minds: Building the Library without Walls," College \& Research Libraries 47:541 (Nov. 1986).

19. Robert Spinrad, "Dynamic Documents," Information Technology Quarterly (Harvard) 7:18 (Spring 1988).

20. Dana Cartwright, Steven W. Gilbert, and Peter Lyman, "Beyond Intellectual Property," Educom Review 24:7-8 (Summer 1989).

21. Ann Okerson, Of Making Many Books There Is No End: Report on Serial Prices for the Association of Research Libraries (Eastchester, N.Y.: April 19, 1989).

22. James Thompson, "Guest Editorial: Journal Costs: Perception and Reality in the Dialogue," College \& Research Libraries 49:482 (Nov. 1988). 